\title{
SANTO TOMÁS Y EL PROGRESO HISTÓRICO EN EL CONOCIMIENTO DE LA VERDAD
}

\author{
Elisa Luque Alcaide \\ Universidad de Navarra
}

\section{INTRODUCCIÓN}

El estudio y la investigación de la historia de la filosofía exige una recta y adecuada interpretación de los filósofos que nos han precedido en el'tiempo. Con esta perspectiva, nos hemos acercado a la obra de Santo Tomás para indagar en ella cómo procedía en la investigación de los «Antiguos», en la doctrina de los que habían indagado acerca de la verdad de los entes.

Hemos elegido, para hacerlo, una obra de madurez, el opúsculo filosófico. De substantiis separatis o De angelis, escrito, según los editores leoninos, entre el 1270 y el $1273 .{ }^{1} \mathrm{La}$ riqueza del pensamiento maduro del Santo en esta «pequeña original obra maestra», según expresa el Prof. Fabro, ${ }^{2}$ será un buen fundamento para indagar en el tema que nos hemos propuesto. James A. Weisheipl afirma que en este Opúsculo, de notable interés para los estudiosos de la filosofía, Santo Tomás enjuicia el pensamiento de los Antiguos en torno a las substancias separadas y da un cuadro de los principales puntos doctrinales comunes de Platón y Aristóteles. ${ }^{3}$ Esta perspectiva del acuerdo entre Platón y Aristóteles, que aparece

1 J,A. Weisheipl, Tommaso d'Aquino-Vita, pensiero, opere, Jaca Book, ediz. italiana a cura di I.Biffi e C. Marabelli, Milano, 1988, p. 321. Remite el A. a Opera omnia, Ediz Leonina, t. 40/D, Roma, 1968, p. 7, \& 3; J.A.Weisheipl, Thomas's Evaluation of Plato and Aristotle, in The New Scholasticism, 48 (1974), pp. 100 124. La mayoría de los AA. están de acuerdo en que es obra genuina, y de los últimos años del Santo. P. Mandonnet, señala los años 1272-1273 como fecha de composición (Bibliographie, p. XIII, n. 20); A. Walz señala 1268-1273 (Angelicum, 16 [1939], fascic. 4); C. Vansteenkiste se inclina por el año 1259 (Bull. Thom., VIII, [1947-53], N. I, 1951, p. 29); A. Lobato, en un reciente estudio se inclina por el año del 1271, durante la estancia de Tomás en París (Introduzione a Le sostanze separate, en Tommaso d'Aquino - Opuscoli filosofici, Città Nuova Ed., Roma, 1989, p. 158).

2 C. Fabro, Presentazione, en Tommaso d'Aquino-Opuscoli filosofici, op.cit., p. 9.

3 J.A. Weisheipl, Tommaso d'Aquino..., op. cit. 
en el De substantiis separatis, es resaltada por el Prof. Fabro, quien expresa que está ya presente en el sorprendente título: De convenientia positionum Aristotelis et Platonis, que hasta entonces no había aparecido en las obras del Doctor Angélico. ${ }^{4}$

Santo Tomás representa una cumbre indiscutible del pensamiento humano; pero sabemos muy bien que la verdad continúa retando al hombre, que ha de seguir desentrañando la riqueza universal que ella encierra. $Y$ esta tarea se presenta hoy dificultada por la reducción historicista de la verdad que ha ocasionado, en trágica: paradoja, la pérdida de la dimensión histórica del proceso de adquisición de la verdad por el hombre. En efecto, reducida la verdad a sus formulaciones en cada momento histórico, el filósofo se ve obligado a iniciar sobre nuevas bases su búsqueda y formulación. Se ha llegado así a la aparente incongruencia de que el planteamiento historicista de la filosofía de la inmanencia, ha forjado la especulación filosófica como empresa ahistórica e individual. ${ }^{5}$

\section{UNA INVESTIGACIÓN DE SANTO TOMÁS}

Es Santo Tomás mismo quien en el cap. XVII del Opúsculo expone la estructura del De substantiis separatis. Lo hace al expresar la investigación que se propone. En una primera parte indagará en los filósofos Antiguos su doctrina acerca del origen, naturaleza y ordenación de las substancias separadas; la segunda parte tratará de la doctrina cristiana acerca del tema. En esta comunicación nos limitaremos a algunos puntos del recorrido que, a través de los filósofos, hace el Aquinate, para ver cómo apoya su investigación en los filósofos anteriores. ${ }^{6}$

En el prólogo de la obra expresa el estudio que se propone: al abordar el tema de la excelencia de los Santos Ángeles, ha decidido comenzar por lo que estimaron los antiguos,

\section{Tommaso d'Aquino - Opuscoli Filosofici, op. cit, Presentazione, p. 18.}

5 J. Arana, La Revolución cientifica y las revoluciones filosóficas, en Anuario Filosófico, XXII/2 (1989), pp. 17-35: en este sugestivo artículo el A. se plantea la diversidad del proceder de la ciencia moderna, que, apoyándose en las conquistas anteriores, ha hecho posible lo que llama una «revolución conservadora», es decir una empresa histórica y colectiva, que ha tenido un avance progresivo; y el modo de plantear el estudio filosófico de la verdad, por otra, que ha desdeñado el trabajo realizado por los filósofos precedentes, y ha partido de bases completamente nuevas. El Prof. C. Fabro alude a la trágica desproporción entre el despliegue de energía especulativa realizado por la filosofía moderna y el empobrecimiento radical de sus logros, que se han ido resolviendo en el vacío: Cfr. Introduzione all'Ateismo Moderno, 2." edizione, Vol. I, Edit. Studium, Roma, 1969, p. 83.

6 «Quia igitur ostensum est quid de substantiis spiritualibus praecipui philosophi Plato et Aristoteles senserunt quantum ad earum originem, conditionem naturae, distinctionis et gubernationis ordinem, et in quo ab eis alii errantes dissenserunt; restat ostenderet quid de singulis habeat christianae religionis assertio»: $D e$ Substantiis separatis seu de Angelorum natura ad Fratrem Reginaldum socium suum carissimum, en Opuscula Philosophica, cura et studio P. Fr. Raymundi M. Spiazzi, O.P., Marietti, Taurini-Romae, 1954, cap. XVII, p. 19. La parte primera (cap. 1-16) es la más amplia ya que, como es sabido, es una de las obras inconclusas del Aquinate. 
de modo que aceptará lo que encuentre de acuerdo con la fe; y rechazará lo que sea incompatible con la doctrina católica. ${ }^{7}$

La primera perspectiva que Santo Tomás nos ofrece es la de la finalidad misma que le ha movido a llevar a cabo la investigación «de los Antiguos»; busca en ellos las luces verdaderas que sus planteamientos le puedan proporcionar acerca del tema que se propone, el conocimiento de los Ángeles. Es la búsqueda de la verdad lo que le ha motivado a recorrer las obras de los filósofos que le han precedido. Es una óptica diametralmente opuesta a la investigación acumulativa y «nocionística» a la que el escepticismo filosófico nos tiene habituado, como describía con acierto Derrick:

«La disciplina académica de la filosofía ha ido convirtiéndose en una disciplina consistente en estudiar filósofos. No es raro encontrar licenciados o doctores en este campo sobre todo lo que ha dicho todo el mundo, desde los sofistas pasando por Descartes, hasta Wittgenstein, e incluso después; pero son - esos doctoresabsolutamente escépticos ante los argumentos que todos estos hombres construyeron en su lucha por alcanzar una certeza».8

Tomás de Aquino, que desea profundizar en la verdad acerca de los Ángeles, acude al pensamiento de «los Antiguos». Se refleja aquí una dimensión destacada de la doctrina tomista; precisamente su confianza en la capacidad de la razón humana para abordar la verdad natural en todos sus ámbitos. En concreto para penetrar en el tema de los Ángeles, es decir de la sustancia espiritual separada, no duda el Aquinate indagar en las obras de los filosófos que vivieron y maduraron sus planteamientos antes de la revelación, con la convicción de que en ellos encontrará afirmaciones verdaderas sobre esa realidad angélica. ${ }^{9}$.

Encontramos también formulada la distinción y armonía entre la verdad, que la razón humana ha sido capaz de hallar a lo largo de siglos de esfuerzo, y la verdad revelada, que la fe nos propone: quid id invenerimus fidei consonum, accipiamus. Afirmación de que en el pensamiento de los antiguos encontraremos luces, penetraciones en la realidad, espiritual en este caso, que estarán en consonancia con las verdades que alcanzamos por medio de la revelación.

Por último, en este proemio Tomás de Aquino expresa la jerarquía entre ambos órdenes de conocimiento. De las verdades que alcanzaron los antiguos, afirma, aceptaremos las que

7 «Intendentes igitur sanctorum Angelorum excellentiam utcumque depromere, incipiendum videtur ab his quae de Angelis antiquitus humana coniectura aestimavit: ut si quid invenerimus fidei consonum, accipiamus; quae vero doctrinae repugnant catholicae, refutemus»: Ibidem, Proemium.

8 C. Derrick, Huid del escepticismo, (Una educación liberal como si la verdad contara para algo), Ed. Encuentro, Madrid, 1982, p. 74.

9 Cfr. E. Gilson, El Tomismo, EUNSA, trad. española F. Múgica, Pamplona, 1978, pp. 297-298: afirma que para Santo Tomás al conocimiento de los Ángelẹs se accede también por la razón natural, ya que en una doctrina en la que la razón última de los seres se obtiene muy a menudo del lugar que ocupan en el universo, el omitirlos rompería el equilibrio del universo. Señala que la doctrina tomista sobre los Ángeles es el desenlace de una lenta evolución, en el curso de la cual convergen elementos heterogéneos; en concreto el A. señala tres fuentes de esa doctrina del Santo: la Revelación, que habla de los Ángeles; las teorías astronómicas aristotélicas que recurren a inteligencias separadas como motoras de los cielos; y las teorías neoplatónicas que trataban de los intermediarios entre Dios y el mundo corpóreo. 
están en consonancia con la fe, y rechazaremos las que se apartan de la doctrina católica; así delimita el criterio de la certeza de la fe como medida ụ́ltima de los hallazgos de la razón.

\section{DESARROLLO HISTÓRICO ACERCA DEL CONOCIMIENTO QUE TENE- MOS DE LOS ÁNGELES}

El Aquinate, indagando en «los Antiguos», nos acerca al progreso en la verdad sobre los Ángeles que históricamente se ha dado. Parte de los primeros filósofos de la naturaleza que se preguntaron sólo por los seres corporales y pusieron el primer principio en los elementos físicos. Llega a la conclusión de que con relación a la finalidad de la indagación propuesta, sobre las substancias espirituales, estos primeros naturalistas, nullas substantias incorporeas esse videbatur, quas Angelos nominamus. ${ }^{10} \mathrm{~A}$ partir de ese comienzo, para superar el nivel naturalista y alcanzar el orden espiritual, hubo de recorrerse una triple vía de la que hace a continuación una síntesis interpretativa. ${ }^{11}$

La primera etapa o vía está representada por Anaxágoras, quien puso un cierto principio incorporal, intelectual, que produce las cosas estableciendo el orden en lo mixto, en las «homeomerías»; para hacerlo, el principio ha de ser él mismo simple y no puede tener naturaleza corporal. Tomás de Aquino reconoce la superioridad de esta opinión frente a las anteriores, que sólo consideraban la naturaleza material. A la vez señala sus deficiencias, ante todo respecto al tema que investiga: al admitir sólo un intelecto separado, ordenador de todo, no alcanzó Anaxágoras a penetrar en las substancias incorpóreas, que llamamos Ángeles; también señala sus límites respecto a la verdad metafísica que él mismo ha alcanzado, el esse como principio universal: ese intelecto separado es sólo ordenador y, como tal, principio de distinción de los entes, no principio universal del esse. ${ }^{12}$

La segunda vía de ascensión hacia el orden espiritual, sostiene Tomás de Aquino, está representada por Platón, que significa una vía superior en la ascensión del nivel de los primeros filósofos de la naturaleza. Partiendo de que, según «los Antiguos», no podía ser conocida la verdad de las cosas, bien porque las cosas corporales están en continuo movimiento, o bien por defecto de los sentidos, puso ciertas naturalezas, separadas del

10 Ibidem, n. 43. Cfr. De potentia, III, art. 1, explicita más la posición de este primer nivel del pensamiento filosófico: los hombres, atraídos primeramente por el aspecto sensible de las cosas, dirigieron su atención a los cambios accidentales, inmediatamente perceptibles; al buscar explicación pensaron que todos los cambios fuesen accidentales de una sola substancia, pensada como un único substrato o materia.

11 Cfr. De potentia, ibidem, en donde describe también el paso al principio espiritual: (los hombres) más tarde se dieron cuenta de la diferencia entre los cambios accidentales y los cambios substanciales y buscaron la causa de los segundos en algo que estuviese fuera de la materia (el odio y la amistad en Empédocles, el intelecto en Anaxágoras); éstos, sin embargo se preguntaban todavía por la razón de ser de una substancia concreta, no del ser en general y, por ello, presuponían siempre una materia anterior a los cambios.

12 «Cum enim existimaret intellectum, quem posuit separatum, non ut universale essendi principium, sed solum principium distinctivum» (De substantiis separatis, cap. I, n. 44). 
movimiento de las cosas, en las cuales permaneciese la verdad sin mutación; alcanzándolas, nuestra alma podría conocer la verdad. ${ }^{13}$

Estudia el Aquinate en esta doctrina el orden jerárquico de seres que obtienen el ser por participación del primer Ens, y que, como es conocido, delimita Platón estructurado en cuatro órdenes, situados entre Dios y los hombres: dioses segundos, intelectos separados, almas celestes y demonios buenos y malos. ${ }^{14}$ Tomás de Aquino, que ha expuesto la doble abstracción -matemática y del universal - que el intelecto realiza en el conocimiento de la verdad, señala las limitaciones de la doctrina platónica: no es necesario que las cosas que el intelecto capta separadamente, tengan el ser separado en la naturaleza de las cosas; de ahí que no es necesario que los universales tengan subsistencia separada de las cosas singulares; y acude al ejemplo de los conceptos matemáticos que no existen fuera de los sensibles, concluyendo que los universales son de la esencia de los mismos particulares. ${ }^{15}$

La tercera vía es la de Aristóteles que, afirma Tomás de Aquino, emprendió su investigación sobre las substancias separadas, por un camino o método más certero y eficaz: es decir, estudiando el movimiento, por medio de la razón y por ejemplos; investigación del intelecto que confronta con la experiencia, destaca. Este método permitió al Filósofo alcanzar por vía racional la existencia del primer motor inmóvil, incorpóreo, con la máxima inteligencia y voluntad. ${ }^{16} \mathrm{Y}$ señala a continuación que, según Aristóteles, entre nosotros y Dios sólo hay un doble orden de substancias intelectuales: las substancias separadas que son fines del movimiento de los cuerpos celestes, y las almas del mundo que se mueven por el apetito y el deseo.

Contrasta esta doctrina con la de Platón y señala, de modo significativo, que, aunque la aristotélica parece más cierta, por no apartarse de las cosas que conocemos por los sentidos, se presenta como menos adecuada que la de Platón; en concreto, no considera como substancias separadas a los demonios, de los que nos consta, afirma el Aquinate, su acción sobre los hombres; al limitar por otra parte el Filósofo las substancias inmateriales al número de las substancias corporales, somete lo superior a lo inferior: no se puede establecer el número de las substancias inmateriales a partir del número y del poder de los movimientos celestes.

Tomás de Aquino deja constancia, una vez más en este Opúsculo, de su fidelidad a la verdad en su investigación, y de la libertad que le proporciona frente a los que le han precedido. Así, señaladas estas carencias de la doctrina aristotélica, se adhiere a la teoría del Estagirita de que el movimiento de los cuerpos celestes está conducido por las substancias separadas e inmateriales que actúan como fin de ese movimiento; y vuelve a asentar que la conclusión de que el número de las substancias inmateriales viene dado por los cuerpos celestes cuyo movimiento impulsan, no se sigue necesariamente. ${ }^{17}$

13 Ibidem, cap. I, n. 45.

14 Cfr. De substantiis separatis, cap. I, n. 46-49.

15 Cfr. De substantiis separatis, cap. I, n. 50.

16 Cfr. De substantiis separatis; cap. II, n. 50-52.

17 Cfr. De substantiis separatis, cap. II, n. 53-55. 
Llega el Aquinate al cap. 3 del Opúsculo en el que traza una espléndida síntesis de los aspectos en que convergen Platón y Aristóteles acerca de las substancias separadas; expresa en este capítulo el ápice de las luces que la Filosofía Antigua le ha proporcionado en su investigación, ${ }^{18}$ y señala los siguientes temas:

a) ambos filósofos están de acuerdo en el modo de ser de las substancias separadas: lo han recibido por participación del Esse supremo;

b) concuerdan también en cuanto a la naturaleza de las mismas, que ambos ven como espirituales, absolutamente privadas de la materia; aunque están compuestas de potencia y acto nam omne participans ens, oportet esse compositum ex potentia et $a c t u$, y añade que, como según Platón, todas las substancias, excepto la suprema, son participantes, es necesario afirmar que todas están compuestas de potencia y acto, según la sentencia de Aristóteles; realiza así el Aquinate el admirable trabajo de enjuiciar rectamente a ambos filósofos y de emplear con acierto sus doctrinas al servicio de la verdad;

c) en cuanto a que participan del gobierno del mundo a través de la divina providencia que alcanza a todos los órdenes inferiores de seres. ${ }^{19}$

Hemos alcanzado el núcleo que nos parece central en la investigación histórica de Santo Tomás; en los capítulos que siguen trata de las posiciones de algunos filósofos posteriores que deterioraron o perdieron esas luces verdaderas que el estudio del tema en «los Antiguos» le ha proporcionado.

En primer lugar señala cómo Avicebrón, con su doctrina de la composición de materia y forma en las substancias separadas, pierde la verdad acerca de la naturaleza de las mismas en que concordaron ambos filósofos griegos. El error de esta teoría consiste en pensar que el elemento potencial de toda criatura que la distingue del Acto puro está en la materia. ${ }^{20}$

Considera después el Aquinate la teoría emanacionista de Avicena por la cual las cosas fluyen del primer principio a través de un proceso necesario y por mediación angélica.

18 C. Fabro resalta «la especial importacia especulativa que tiene el De substantiis separatis en la especulación tomista, en cuanto consagra, esto es, confirma y profundiza, el pensamiento vigoroso de Santo Tomás en sus últimos años como síntesis especulativa de la noción platónica de participación y del binomio atistotélico de acto y potencia (forma y materia)», en San Tommaso-Opuscoli Filosofici, op. cit., Presentazione, p. 19.

19 De substantiis separatis, vid. cap. 3. En el cap. 4 describe el Santo los aspectos en que difieren ambos filósofos: de algún modo ya los hemos enunciado en este trabajo: diferencia en el número de órdenes de substancias separadas; fijación del número de las mismas en Aristóteles de acuerdo con los movimientos celestes; Aristóteles no consideró a los demonios como substancias separadas, en contraste con la doctrina platónica.

20 De substantiis separatis, vid. cap. 5-9. Remite el Aquinate al libro Fons vitae. Cfr., sobre este tema: S. Vanni Rovighi, L'antropologia filosofica di San Tommaso d'Aquino, Ed. Vita e Pensiero, 2. ${ }^{a}$ ed. 1982, p. 13: destaca la originalidad y coherencia del Santo en rechazar esta doctrina que, al acentuar la libertad divina en la creación, había sido bien acogida por otros pensadores cristianos, y remite a A. Masnovo, Da Guglielmo d'Auvergne a San Tommaso d'Aquino, vol. II, Pubblicazioni dell'Università Cattolica del Sacro Cuore, Milano, 3 vols.,1933-1943; y P. Ferrer Rodríguez, La inmaterialidad de las substancias espirituales (Santo Tomás versus Avicebrón), en Excerpta e Dissertationibus in Sacra Theologia, 15 (Pamplona, 1988) pp. 151221 , con bibliografía 
Tomás de Aquino expresa los argumentos que le llevan a sostener racionalmente la creación como producción de los entes inmediata y libremente por Dios a partir de la nada. ${ }^{21}$

La tercera verdad que el Aquinate había alcanzado en «los Antiguos» era la de la intervención de las substancias separadas en los planes de la providencia divina. También ha sufrido un retroceso en algunos filósofos posteriores. Así lo expresa Tomás de Aquino: afirmaron algunos que ni Dios ni las substancias inmateriales tenían conocimiento del singular, y no podían tener providencia de los inferiores y principalmente de los actos humanos; y el Aquinate se extiende en el estudio de la providencia de Dios analizando el ámbito del conocer divino que alcanza a todas las cosas, y de la providencia divina que alcanza también a lo pequeño. ${ }^{22}$ Este estudio le permite expresar con su concisión habitual la verdad acerca de la providencia divina, que es universal e inmutable, y ordena a los seres según su naturaleza, determinada ad unum o con intervención de la libertad. ${ }^{23}$

Finalmente dedica el cap. 16, último de la primera parte del Opúsculo, a la doctrina de los maniqueos; en ella confluyen, afirma, el triple error acerca de las substancias separadas: sobre su origen, naturaleza y sobre la función que les corresponde en el orden de la providencia.

\section{NOTAS ACERCA DEL PROGRESO HISTÓRICO EN EL CONOCIMIENTO DE LA VERDAD SOBRE LOS ÁNGELES}

Pasamos ahora a enunciar las notas que podemos deducir del recorrido que hemos visto hacer a Tomás de Aquino al investigar en «los Antiguos» sobre el tema de los Ángeles:

21 De substantiis separatis, vid. cap. 10-12: en esta teoría participan de algún modo los neoplatónicos y Orígenes, que el Aquinate expone. La libertad de Dios en la creación va afirmada en De potentia, III. art. 4: «Nos autem ponimus quod a Deo procedunt res per modum scientiae et intellectus, secundum quem modum nihil prohibet ab uno primo et simplici Deo multitudinem immediate provenire»: cfr. S. Vanni Rovighi, op.cit, pp. 9-10; en la cita 5, de la p. 10 afirma esta A. que en el De substantiis separatis Tomás de Aquino resume en pocas líneas lo esencial de la doctrina aviceniana sobre la emanación de las cosas desde Dios, y remite a E. Gilson, Pourquoi St. Thomas a critiqué St. Augustin, en Archives d'Histoire Doctrinale et Littéraire du Moyen Âge, Paris, 1, (1926-27), pp. 5-127.

22 De substantiis separatis, cap. 13-15. Es en el cap. 14 donde el Aquinate expone este análisis y en él expresa de modo admirable las verdades que Platón y Aristóteles alcanzaron encuadradas en la verdad que ha alcanzado Tomás de Aquino en su doctrina filosófica de Dios ipsum esse y de la participación de las creaturas en el esse. «Ut enim supra habitum est, Dei substantia est ipsum eius esse. Nos est autem in eo aliud esse, atque aliud intelligere», expresa en el n. 120 y concluye en el n. 127: «Patet igitur praedicta verba Philosophi diligenter consideranti, quod nos est intentio eius excludere a Deo simpliciter aliarum rerum cognitionem[...]»; afirmando que Dios «Intelligit autem omnia alia a se intelligendo se ipsum, inquantum ipsius esse est universale et fontale principium omnis esse, et suum intelligere quaedam universalis radix intelligendi, omnem intelligentiam comprehendentes».

23 «Concedendum est igitur quod divina providentia, ab aeterno praeexistens, causa est omnium effectuum qui secundum ipsa fiunt, et qui immutabili dispositione ab ipsa procedunt. Nec tamen sic omnes procedunt ut necessarii sint, sed sicut eius providentia disponit ut tales effectus fiant, ita etiam disponit ut effectus quidam sint necessarii, ad quos causas proprias ex necessitate agentes ordinavit, quidam vero contingentes, ad quos causas proprias contingentes ordinavit»: De substantiis separatis, cap. 15, n. 137. 
a) En primer lugar destaca la finalidad del estudio emprendido por el Aquinate: buscar en su doctrina la verdad acerca del tema propuesto. $\mathrm{Al}$ hacer esa búsqueda llevado por la meta de alcanzar la verdad, le hemos visto acoger o rechazar lo que de valioso le presentaba cada uno de los filósofos que estudia, ejercitando la libertad en la investigación que realiza. ${ }^{24}$

b) En segundo lugar, queda reflejado en el Opúsculo estudiado, la capacidad del intelecto humano, abierto a la verdad universal, pero con limitaciones que el estudio histórico confirma: la verdad acerca de los Ángeles aparece en un progreso esforzado, costoso, a lo largo del tiempo, y no lineal.

La posibilidad de error, de desviarse de la verdad, queda reflejada en el Opúsculo: en los filósofos de la naturaleza; también en Platón y en Aristóteles, como hemos destacado; ni siquiera la luz de la revelación es garantía suficiente, en algunos casos, para impedir esa desviación: no lo ha sido en la Ley Antigua, ya que usque ad Iudaeos Dei cultores perveniret, quorum Sadducaei dicebant non esse Angelum neque spiritum (cap. 1, n. 43); tampoco en la Ley Nueva: es el caso de Orígenes ponentis omnes substantias spirituales aequales esse creatas (cap. 12 ab initio), posición de la que juzga manifeste continet vanitatem, ya que Deus diversa et inaequalia in esse produxit, attendens ad id quod requirit perfectio universi (ibidem, n. 114).

c) Sobre ambos presupuestos, el avance que hemos visto realizarse ha partido siempre de una verdad, una luz que incita al trabajo de la búsqueda, y de una carencia que se presenta como meta que ha de ser superada: así lo ha descrito Tomás de Aquino al estudiar a Platón y a Aristóteles; también así ha actuado el Aquinate que, precisando los errores que ocasionaron la pérdida de las verdades halladas por Platón y Aristóteles, hace una exposición doctrinal de honda calidad.

d) Finalmente señalamos algunos aspectos del trabajo realizado por Tomás de Aquino para investigar la verdad sobre los Ángeles, tal como se manifiesta en el Opúsculo estudiado:

1. Ha partido de un trabajo serio de estudio en las obras de los que le precedieron: de opinionis Platonis et Aristotelis circa substantias separatas ex diversis scripturis collegimus, afirma en el cap. 4 al hacer la síntesis de las doctrinas de ambos filósofos; ${ }^{25}$

24 Para C. Vansteenkiste, «la libertad intelectual está basada sobre la conciencia del hecho de que la verdad es objetiva y no pertenece a un autor, sino que se presenta como una conquista de la entera humanidad a lo largo de su historia»: en Il metodo di san Tommaso, en Varios Autores, Le ragioni del tomismo, Ed. Ares, Milano, 1979, p. 173.

25 Cfr. E. Luque Alcaide,Il tomismo romano nel settecento: San Tommaso nel Bullario di Benedetto XIV, en Atti del IX Congresso Tomistico Internazionale, Editrice Poliglota Vaticana, Città del Vaticano 1991, vol. VI, pp. 231-245:Benedicto XIV pone de manifiesto en la Constitución Sollicita ac provida, del 9 luglio 1753, . otra característica del Santo al enfrentarse a diversos autores; Santo Tomás que es presentado como maestro de todos los que buscan y sostienen la verdad, al hacerlo, y verse obligado a rechazar los errores de filósofos y de teólogos, lo realizaba de modo afable, respetuoso con los que disentían de él. No tocamos aquí este aspecto, aunque también está presente en el De substantiis separatis. 
2. Ha seguido un método de estudio, garantía de certeza ante la posibilidad de error que está presente en la investigación; método que él mismo señala en Aristóteles: al partir de la consideración del movimiento para tratar de las substancias separadas, lo hizo et ratione et exemplis (cap. 2): estudio racional en continuidad con los datos aportados por la experiencia.

3. Por último, sobre el tema del que Tomás de Aquino se ocupa - los Ángeles- se proyecta con claridad la luz de la fe y, por ello, al emprender su estudio en «los Antiguos»,' sostiene: ut si quid invenimus fidei consonum, accipiamus; quae vero doctrinae repugnant catholicae, refutemus (Proemium, n. 42). 